\title{
Urban waste flows and their potential for a circular economy model at city-region level
}

\author{
Vanessa Zeller $^{\mathrm{a}, *}$, Edgar Towa ${ }^{\mathrm{a}, \mathrm{b}}$, Marc Degrez $^{\mathrm{b}}$, Wouter M.J. Achten ${ }^{\mathrm{a}, *}$ \\ a Institute for Environmental Management and Land-use Planning, Université Libre de Bruxelles (ULB), Av. F.D. Roosevelt 50, 1050 Brussels, Belgium \\ b 4MAT Department, Université Libre de Bruxelles (ULB), Av. F.D. Roosevelt 50, 1050 Brussels, Belgium
}

\section{A R T I C L E I N F O}

\section{Article history:}

Received 11 June 2018

Revised 28 September 2018

Accepted 20 October 2018

\section{Keywords:}

Waste input-output

Waste supply and use

Urban waste metabolism

Circular economy

Waste flow analysis

Waste performance

\begin{abstract}
A B S T R A C T
To enable cities to become more circular, i.e. close material cycles, decision-makers need detailed data about the production and treatment of waste. At city level, conventional statistics on waste are often incomplete or lack detail. Waste input-output accounting offers an alternative, using waste supply and use tables to create detailed inventories of economy-wide flows of waste. In this study we develop such tables for the city-region of Brussels (Belgium) and use them to analyse the urban waste metabolism in terms of waste flows, waste production intensity and waste treatment performance.

The waste flow analysis revealed: the amount of collected waste; the proportion contributed by individual sectors; the material composition of waste flows and the location of treatment. Currently, around $50 \%$ of the 1.5 million tons of waste collected in Brussels is treated in local facilities. However, less than $1 \%$ of the collected waste is used in a way that closes material cycles within city limits. The waste performance analysis reveals that the construction sector had the highest waste production intensity and the household sector the highest incineration intensity. In terms of waste prevention and local valorisation potential, we identified flows and sectors for future targeting, one of the most promising being food waste. We conclude that the urban context can restrict the local valorisation of waste flows, thus we see the role of cities such as Brussels in a circular economy as mainly contributing to the closing of material cycles at national or even global level.
\end{abstract}

(ㄷ) 2018 Published by Elsevier Ltd.

\section{Introduction}

\subsection{Waste flows and the circular economy}

The global amounts of waste generated are estimated between 7 and 10 billion tons per year (Wilson et al., 2015). The amount of solid waste recorded in official statistics is around 3.2 billion tons. It is estimated that from this amount $47 \%$ is landfilled, $31 \%$ recycled and $22 \%$ incinerated (Tisserant et al., 2017). Thus, almost $70 \%$ of waste is currently not reused or recycled. This represents an enormous loss of resources and explains the high pressure on global primary resources. However, not only the depletion of resources constitutes an environmental (as well as socio-economic) challenge, but also the impacts from the treatment of the waste represent negative externalities. First of all, environmental impacts from uncontrolled disposal of waste into the environment, for example accumulation of micro plastics in the oceans threatening

\footnotetext{
* Corresponding authors.

E-mail addresses: vzeller@ulb.ac.be (V. Zeller), wouter.achten@ulb.ac.be (W.M.J. Achten)
}

the marine fauna (Avio et al., 2017). But also, environmental impacts from controlled waste treatment processes create environmental problems, for example, methane from landfills that constitute around $4 \%$ of worldwide greenhouse gas emissions (Ackerman, 2000) or the emissions of air pollutants from waste incineration (Lu et al., 2017).

In order to reduce environmental pressure from waste, resource and waste management principles have been introduced into waste legislation. The most important principle implemented in the European waste legislation is the waste hierarchy establishing a priority order from prevention, preparation for reuse, recycling and energy recovery to disposal activities, such as landfilling (EC, 2008). The waste hierarchy is a generalised, and widely accepted, environmental ranking where prevention is considered to be the most environment-friendly and landfill the least environmentfriendly alternative. However, results from life cycle assessments (LCA) have shown that such generalization is problematic and that environmental performances show strong dependency on local specificities of the waste management systems (Laurent et al., 2014). Also article $4(2)$ of the Waste Framework Directive (2008/98/EC) allows deviations from the waste hierarchy where this is justified by LCA results. 
Currently, the so-called circular economy (CE) concepts are promoted to achieve more waste prevention and better resource management by extending and closing material cycles. CE concepts are promoted at European level through the Circular Economy Package, adopted by the EC in 2015, including legislative proposals and other initiatives (EC, 2015). Important actions are the 2030 targets for recycling (65\% for municipal solid waste (MSW), $70 \%$ for construction and demolition (C\&D) waste, $75 \%$ for packaging waste), landfill restrictions (MSW reduction to $10 \%$ ), promotion of industrial symbiosis and eco-design. Even if waste prevention at source has highest priority, quantitative waste prevention targets (except for food waste) are still lacking in European legislation.

\subsection{Circular economy at city scale}

Due to the dynamic population and economic development in cities, the environmental pressure in terms of resource consumption and waste generation is especially high in cities (Hoornweg et al., 2013). To improve local performances, many cities turning towards CE concepts, for example organised in the circular cities network. A current review of CE initiatives around the globe identified 83 cities that promote $\mathrm{CE}$, but with different targets and interests (Petit-Boix and Leipold, 2018).

Proximity of resources and people, a sufficient scale for effective markets (supply ${ }^{1}$ and demand) and the ability to shape urban planning and policy are seen as factors for the unique position of cities in CE. The geographic proximity of supply and demand is expected to have environmental benefits through more efficient material collection cycles and more efficient reverse logistic (Ellen MacArthur Foundation, 2017). This proximity advantage is also frequently mentioned in the context of urban symbiosis, which is based on the 'synergistic opportunity arising from the geographic proximity of urban waste sources and potential industrial users' through exchange of waste materials for environmental benefit (Van Berkel et al., 2009).

Although environmental benefits are mentioned in the context of urban CE, few environmental assessments of urban initiatives are available and complementary CE-related environmental research is rarely applied at city level (Petit-Boix and Leipold, 2018). However, some environmental assessments of CE developments at city level are available for Asian cities. For example, Fang et al. (2017) found resources and carbon footprint savings in one of China's national pilot cities for CE. Sun et al. (2017) found life cycle environmental benefits of urban symbiosis within a typical industrial city in China and Geng et al. (2010) found $\mathrm{CO}_{2}$ reductions for urban symbiosis scenarios in Kawasaki (Japan).

Comparative environmental assessments of CE activities between the city and larger scales are less frequent. Wang et al. (2018) evaluated the performance of 40 cities in China based on an index system for CE developments (considering mainly environmental criteria) and found higher growth of CE in the pilot cities than in the rest of the country. Other comparative analyses are carried out for specific CE initiatives within cities, for example, for urban agriculture. Comparisons of urban and conventional agricultural systems have shown environmental benefits for certain types of urban agricultural systems (Goldstein et al., 2016). However, these studies did not systematically investigate the use of urban biowaste. The case studies investigated by Sanyé-Mengual et al. $(2013,2015)$ found a reduction of embodied greenhouse gases from reduced transport, packaging, and food distribution losses.

\footnotetext{
1 The sufficient market scale for waste/resources at city level is also discussed in the context of 'urban mining'. Urban mining involves the systematic recovery or extraction of materials from urban areas where large stocks of materials are found, in particular in buildings and infrastructure, end-of-life products, packaging material, and biomass (Li, 2015).
}

However, the question about the impact of the geographical scale is not only an environmental one. It is also highly relevant for techno-economic feasibility of CE initiatives. Sterr and Ott (2004) state that "the "right size" is the minimal size in which outputs can be retransformed into desired inputs, thereby adequately closing material loops'. In their case study in an industrial region, any kind of material could be recycled within the regional boundaries, except of metals. However, the size of the market needs to be sufficiently large (critical mass) to sustain specialized industries and to provide economically viable CE solutions.

Chen et al. (2012) found that the size of 'recycling boundaries' depends on the type of waste. For example, waste oil, metal, plastics, paper, and waste electrical and electronic equipment (WEEE), are circulated in large regions (large recycling boundaries), whereas organic wastes, mixed MSW, and demolition wastes, are suitable for local recycling and recovery. According to the analysis of Chen et al. (2014), the determinants of recycling boundaries are the density of separated waste and the unit transportation/treatment cost. Waste with high market value, accumulated at low density and low unit cost of transportation/treatment, such as metal and glass, are typically recycled at large scale. Waste with low market value accumulated at high density and high unit cost and transportation/treatment (residual MSW, food waste and bulky waste) are more suited for local recycling. However, the appropriate size of scale must be determined based on specific local conditions.

\subsection{Waste and CE strategy in Brussels}

Since 2016 Brussels has a Regional Program for a Circular Economy (PREC, 2016) that includes a set of transversal, sectorial, territorial and governance measures to support the city's CE transition. The dematerialisation of the economy, implementation of extended product cycles and the reduction of environmental impacts are defined as final environmental targets of the plan. However, the local economic stimulation, i.e. the creation of local jobs and local value chains are the central criteria of the program. The sectorial measures target priority sectors like construction, resource \& waste, logistics (transport), commerce and food. For the resource $\&$ waste sector, repair and reuse are identified as core actions of local CE.

The CE program is closely interlinked with Brussels' Waste Plan. The current 4th Waste Plan (Bruxelles Environnement, 2010) includes a waste prevention program, targets for separate collection and targets for the recycling of MSW and C\&D waste. It also contains quantitative waste prevention targets for food, paper, packaging, diapers, garden waste and other waste categories from households and economic sectors. In 2010, a legal obligation became effective to separately collect the recyclable fractions of household waste. In 2014 the legal obligation was extended to economic activities. Currently, the 5th Waste Plan is under development which focusses on CE and a zero waste strategy (Region de Bruxelles-Capitale, 2018).

Despite the legal framework and dedicated programs, the monitoring report about MSW management in Belgium shows a low overall recycling rate for Brussels (Gentil, 2013). Also more recent datasets (Eurostat, 2018a) show an overall MSW recycling rate of around $27 \%$ for Brussels while the average Belgian performance was 54\% in 2013. In Gentil (2013) the low performance is explained by the lack of infrastructure for the treatment of organic waste and lack of collection/recycling infrastructure related to the high urban density.

The city's Waste Plan (Bruxelles Environnement, 2010) states a number of constraints and challenges for the local waste management sector such as the high population density (7,434 persons per $\mathrm{km}^{2}$ (Eurostat, 2018b), the small territory (only $161 \mathrm{~km}^{2}$ ) and the highly urbanized terrain (residential and service sector land use 
of $63 \%$ (Eurostat, 2017)). These conditions limit the availability of sites and the infrastructure network necessary to build new sorting or recycling facilities. The fact that most people live in multiapartment buildings and have no access to a private garden (share of apartments $47 \%$ of the 517.000 houses (Bruxelles Environnement, 2010)) is considered as a constraint for an efficient waste separation and storage. The city's economy is characterised by a high share of service and public sector ( $90 \%$ of gross value added (Eurostat, 2018c)) and by a small company size. Since most companies are integrated in the urban network, it is difficult to monitor the waste produced by these companies.

\subsection{Data availability, accounting frameworks and analytical methods}

In order to study the development of innovative waste management options and implementation of CE models, detailed information on current and future waste flows is needed. This requires the availability of (i) detailed waste (statistical) data on the amount of waste generated, collected and treated, (ii) accounting frameworks to link waste with other relevant flows (production/consumption) in a coherent manner and (iii) analytical tools to assess performances.

Regarding data availability, Hage and Söderholm (2008) state that waste management analyses should rely on local data, but that data availability at city-region level is often problematic. Also Prendeville et al. (2017) identified a lack of access to data as a key barrier to the implementation of initiatives in cities. More specifically, the availability of waste (statistical) data at the local and regional scale is challenging in terms of data coverage (households and economic activities), detail (waste composition), spatial/sector resolution and temporal completeness (availability of time series).

Regarding the availability of accounting frameworks that link waste with production and consumption data, methodological progress has been achieved in the last years and an international standard, the system of environmental economic accounts (SEEA, 2014) has been developed. Economy-wide material flow accountings (EW-MFA) which are published by most European countries since 2014 , are part of this framework. These datasets have improved the data availability on physical material flows, but data is highly aggregated and reported at country scale only. For Brussels, a metabolism study is available that has used the EW-MFA framework (Athanassiadis et al., 2016). The solid material inputs, addition to the net stock, and the output flows (exports) were quantified and complemented by an energy and water balance (reference year 2011).

More detailed datasets in terms of sector resolution are input-output (IO) frameworks, which are also part of the SEEA. In conventional IO frameworks, product and service flows between economic sectors and towards the final demand sectors are measured in monetary terms. Waste treatment services are accounted, but flows of waste (without positive monetary value) are not available. In order to account for waste flows and to assess impacts of waste treatment processes Nakamura and Kondo (2002) developed the waste input-output model (WIO model). It is a conceptual framework to include physical waste flows into the monetary IO-framework. The WIO model was further developed into several directions: (i) towards a model where also the product flows are accounted in physical units (Nakamura et al., 2007), (ii) towards a model where waste flows are integrated into a monetary supply and use model (Lenzen and Reynolds, 2014) and towards an multiregional monetary supply and use model (Fry et al., 2016).

Although the theoretical foundation of WIO models and the development towards material flows accountings have been introduced since more than 15 years, to date only few databases are available that provide complementary physical and monetary data. An exception is the EXIOBASE database, a global multi-regional environmentally extended IO database, available in a monetary and physical (hybrid) version (Tukker et al., 2013; Wood et al., 2014). At the sub-national level, for example the city-level, such detailed IO-datasets, but even the aggregated EW-MFA are hardly available.

To analyse product and waste flows at the scale of an economy, material flow analysis (MFA) and input-output analysis (IOA) are used as analytical methods.

Material Flow Analysis is "a systematic assessment of the flows and stocks of materials within a system defined in space and time"' (Brunner and Rechberger, 2004). The basic principle of MFA is the mass balance stating that the inputs into a system must equal the outputs (i.e. law of conservation of matter/energy). Regarding its original area of application, Brunner and Rechberger (2004) specify (i) the metabolism of cities and (ii) the analysis of pollutant pathways. Guibrunet et al. (2016) define urban metabolism as "framework that takes material flows as the unit of analysis to describe patterns of natural resources transformation in cities". The urban metabolism gives a holistic view on all activities in a city including all inputs, stocks, and outputs of materials and energy. While the standard urban metabolism study represents an analysis of the status quo at a certain time point, recently the framework of dynamic urban metabolism has been developed (Athanassiadis et al., 2017).

The urban metabolism aims to give a general picture of flows, one of the output flows being waste flows. The waste metabolism is a type of analysis that studies specifically the flows of waste from generation to treatment. D'Alisa et al. (2012) suggest the use of new indicators to describe the waste metabolism: the metabolic rate of waste and the density of waste. The waste metabolic rate indicates the pace of waste generated or disposed per hour of human activity. The density of waste indicates the amount of waste generated, separately collected or disposed per day in a given area. Browne et al. (2009) suggest to use the materials metabolic inefficiency indicator which relates the final disposal of material and product wastes to consumption in order to determine sectoral inefficiency. The use of new waste performance indicators and the graphical representation of waste flows as metabolic network composed of flows and functional nodes (treatment facilities) are the main characteristics of the waste metabolic analysis conducted by Chifari et al. (2016).

(Environmentally extended) input-output analysis (EE-IOA) is an analytical method to calculate direct and indirect economic and environmental impacts induced by final consumption. When input-output analyses (IOA) are applied to waste input-output models, the generation and treatment of physical waste flows can be calculated. Recent examples of such studies, called waste footprints, include the analysis of solid waste generation and treatment at global level (Tisserant et al., 2017), cumulative waste production induced by Australian consumers (Fry et al., 2016) or waste induced by consumption of Tokyo residents (Tsukui et al., 2015). Waste performance indicators that can be derived from waste IOA are the multipliers from the direct and total requirement matrices that determine the waste production and treatment intensity of sectors. Fry et al. (2016), for example, use the waste production multipliers ( $\mathrm{t} / \$$ millions) to compare the sectoral waste production intensity and found significant differences between two domestic regions.

\subsection{Objective and scope of the study}

The aim of this research is to analyse the current state of Brussels' waste management system and to identify its waste prevention and CE valorisation potential. The scope of the study includes all kind of non-hazardous, solid waste collected from households and economic activities. We develop waste supply 
and use tables for Brussels and use this framework it to analyse the city's waste metabolism, because it provides an economy-wide scope while maintaining the high sector detail that is required for an analysis of waste performance and valorisation potential. Section 2 presents the data and method used to construct waste supply and use tables at the city level. Section 3 presents results from the waste metabolic analysis, including the waste flow tables and a Sankey diagram, as well as waste performance indicators. We also discuss the outcomes in terms of $\mathrm{CE}$ valorisation potential. Section 4 presents the conclusions that can be drawn from the different analyses.

\section{Data and methods}

In this study, we use the WIO framework to perform the analysis of waste flow and waste performance. The various waste tables that are part of the accounting framework offer different perspectives on the flows of waste: a waste-type, sector- and treatment-specific perspective. The first step of our approach was to complete data and to estimate the total amount of collected waste (Section 2.1). This completed dataset fed into the second step, the construction of the detailed waste supply and use tables (2.2). In step 3, we developed the waste treatment allocation table for Brussels (2.3) followed by the construction of the waste supply to treatment table (2.4). In the last step, we aggregated data from the different tables to visualise them in a Sankey diagram (2.5). The waste performance indicators selected in this study are presented in 2.6 .

\subsection{Data collection and treatment}

\subsubsection{Waste statistical data}

Due to its status as city-region, statistical data on MSW is available. MSW, which represents around $30 \%$ of the total waste, includes household and similar commercial, industrial and institutional waste collected by or on behalf of municipal authorities. Thus, the fractions not similar to household waste (C\&D waste, metal scraps, vehicles, etc.) or the waste collected by private operators (e.g. bulky or WEEE) are not included. For these waste fractions only estimations of the waste amounts exist, presented in highly aggregated waste categories (for example 'waste from companies and administration', 'other waste').

In order to improve the initial data situation and to determine the total amount of solid, non-hazardous waste collected in Brussels, we collected data from the three entities involved in the waste management or in the monitoring of waste data: (1) the regional agency 'Bruxelles-Propreté' who is the main collector of MSW, (2) 'Bruxelles Environnement', the environmental administration of Brussels in charge of the waste register monitoring all waste types that need to be registered and (3) the statistical office 'Recydata' that monitors waste flows collected by private collectors (RECYDATA, 2014). The collected datasets were analysed and then combined into a joint database (Towa et al., 2017). It contains detailed data on solid, non-hazardous waste collected in 2010 and 2014 and is available in two formats: The first one represents the waste collection system operating in Brussels where waste data is measured in, for example, tons of mixed residual waste collected in white bags/container. The second format is waste-type specific and represents materials, such as glass, inert, metals, etc. This waste-type specific dataset was calculated from the original data by applying waste composition ratios from composition analyses (Agence Bruxelles Proprété (ABP), 2015; RECYDATA, 2017). Table 1 presents the amounts of waste in the waste-type specific format.
Table 1

Total waste quantities collected in Brussels in 2010 and 2014.

\begin{tabular}{llll}
\hline & 2010 (ton) & 2014 (ton) & Variation (\%) \\
\hline Glass & 38,507 & 39,097 & 1.5 \\
Inert & 625,244 & 652,869 & 4.4 \\
Metals & 191,144 & 200,317 & 4.8 \\
Food waste & 160,182 & 160,014 & -0.1 \\
Paper \& cardboard & 192,170 & 186,900 & -2.7 \\
Plastic & 105,313 & 102,625 & -2.6 \\
Textile & 23,316 & 25,660 & 10.1 \\
Wood & 64,131 & 63,276 & -1.3 \\
Garden & 35,103 & 41,305 & 17.7 \\
Other & 82,450 & 66,558 & -19.3 \\
Total & $1,517,561$ & $1,538,620$ & 1.4 \\
\hline
\end{tabular}

\subsubsection{Input-output tables}

For Belgium, interregional supply and use tables as well as input-output tables are available, which model the economic flows of products between Brussels, the two other Belgian regions (i.e. the Walloon and Flemish region), Europe and non-Europe. The original interregional model available from the Belgian statistical authorities (BFP et al., 2015), was developed by disaggregating the national input-output system by means of top-down methods and consistent with the Regional Accounts. The regional supply tables specify the monetary output for each economic sector in the three Belgian regions. The model was extended by environmental data and coupled with EXIOBASE for the import flows (Zeller, 2017). In the extended model, Brussels' economy is structured into 81 sectors (plus households) that produce and consume 81 types of products and services. This economic input-output framework that follows the sector classification, listed in the supplementary material (supplement 1 ), builds the general structure for the developed waste extensions (2.2 and 2.4).

\subsection{Waste supply and use tables}

This section describes the construction of the waste supply and use tables. In our accounting based on waste statistical data, waste is defined in a narrow sense without by-products or recovered products or materials ${ }^{2}$. Table 2 shows the layout of the waste supply table $(\mathrm{W}(\mathrm{S}))$ for Brussels. It is a waste type by economic activity table whose components $w(s)_{k j}$ and $w(s)_{k f}$ show the amount of waste type $k$ (in ton) generated by an economic activity $j$ or by the final demand sectors $f$ (i.e. households). The data and methodology to construct the waste supply table for Brussels 81 economic activities is documented in (Zeller et al., 2018). In brief, we distributed the statistical data from Table 1 over economic activities and households based on a wastetype specific allocation key. To derive this key, we calculated sectorspecific waste intensities from the Belgian dataset in EXIOBASE v. 2 (NTNU et al., 2015) and scaled them to the economic output of each sector that is given in Brussels' supply data (BFP et al., 2015). The results, i.e. the estimated amounts per type of waste and per sector, are then expressed as percentage contributions to the total waste generation for a specific type of waste. For example, the allocation key for food waste allocates $8 \%$ of the food waste from economic activities to the hotels, restaurants and catering sector (Horeca).

The total waste supply $w(s)_{k}$ is given by

$w(s)_{k}=\sum_{j} w(s)_{k j}+w(s)_{k f}$

\footnotetext{
${ }^{2}$ Waste that is sent to reuse and recovery is included, for example plastic waste that is sent to a sorting facility. The recovered materials from a treatment activity, i.e. the outputs of the material recovery sector (for example sorted and pressed PET) that are going to be used in the manufacturing sector (for example plastic recycling sector) are not additionally accounted as waste, but as an economic product flow. Byproducts constitute a fraction of around $15 \%$ of the total products supplied in Brussels in 2010 (based on the economic value).
} 
Table 2

Structure of the waste supply table.

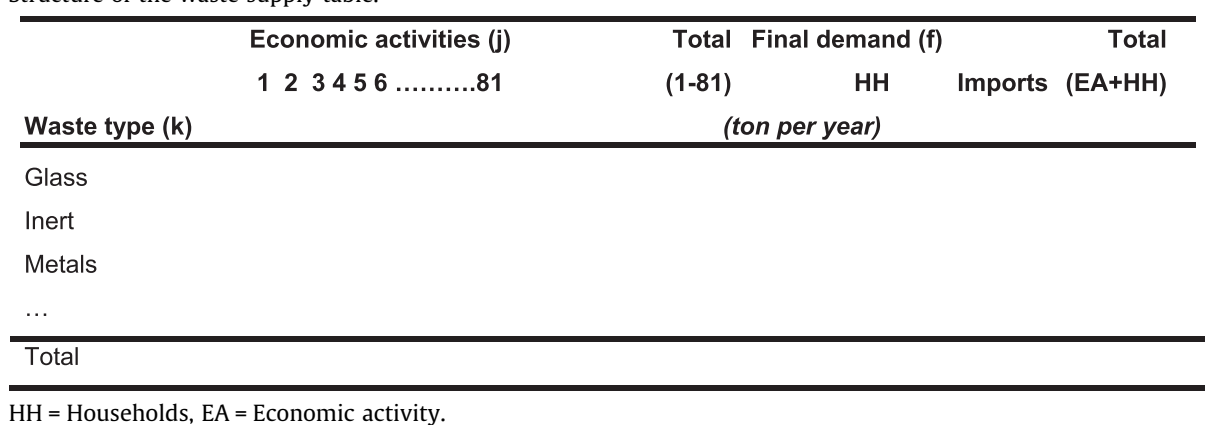

Table 3

Structure of the waste use table.

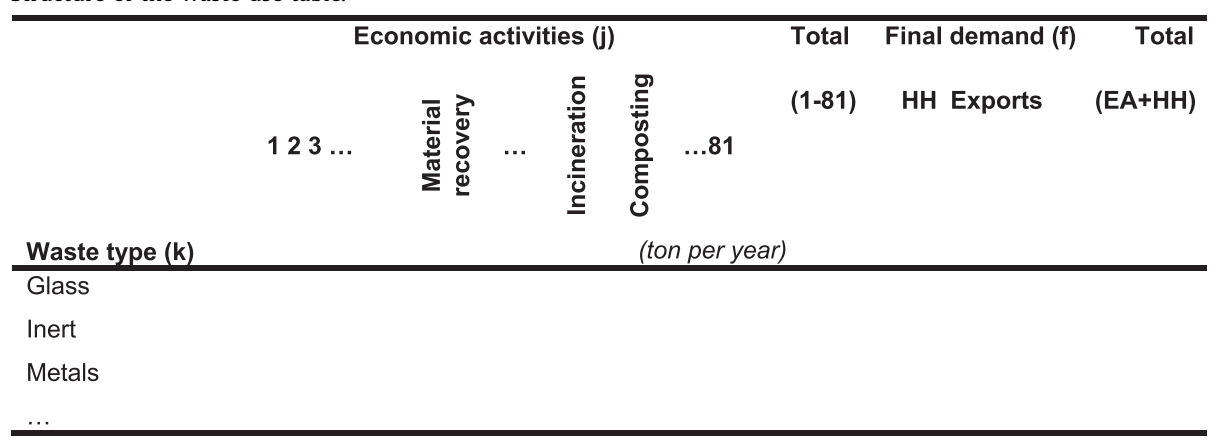

$\mathrm{HH}=$ Households, $\mathrm{EA}=$ Economic activity.

Table 3 shows the structure of the waste use table $(W(U))$. It is a waste type by economic activity table whose components show the use of waste $w(u)_{k j}$ in the local waste treatment sectors or the use of waste $w(u)_{k f}$ in an exterior waste treatment sector (i.e. waste export). Compared to other authors (Nakamura and Kondo, 2002), we account the use of waste only in a waste treatment activity, not in another sector. This difference is closely linked to the definition of waste given above: When by-products and recovered materials are not included, only the conventional waste treatment sectors use waste as an input.

The total amount of waste treated $w(u)_{k}$ is given by

$w(u)_{k}=\sum_{j} w(u)_{k j}+w(u)_{k f}$

The waste treatment sector in Brussels consists of the material recovery, incineration and composting sector. Other possible waste treatment sectors (e.g. anaerobic digestion or landfill) do not exist in Brussels and are therefore not mentioned as economic activities in Table 3. The material recovery sector is a heterogeneous sector grouping (i) dismantling activities and (ii) mechanical or chemical transformation processes, also including separating and sorting of recoverable materials (code 37 in NACE rev.1.1). The sector is called 'preparation for material recovery' in the following in order to emphasize that the activities carried out in Brussels are mainly separation, sorting and dismantling activities.

In order to determine the input-output flows of this sector, we collected physical and economic data from companies assigned to this sector ${ }^{3}$. The total amounts of waste incinerated and composted

\footnotetext{
${ }^{3}$ Companies assigned to this sector are 4 private companies with sites in Brussels and active in the separation of C\&D, bulky and metal waste (using around $80 \%$ of the waste treated by this sector); 1 private-public company sorting plastic bottles, metal packaging and drink cartons (PMD), paper and cardboard; around 10 small social work integration social enterprises active in the dismantling of WEEE and sorting of bulky and textile waste.
}

are published in annual reports (Bruxelles Propreté, 2014). The material composition of waste incinerated was derived from waste bags/container composition analyses (Agence Bruxelles Proprété (ABP), 2015; RECYDATA, 2017). The amount of exported waste was calculated by subtracting the amounts of waste treated in Brussels from the total amounts of waste collected. Thus, in the waste use table, the export column is a balancing item and represents the theoretical direct export of waste. When accounting also for the export of recovered products from the local material recovery sector (for example the sorted PET), the export share is significantly higher.

\subsection{Waste treatment allocation table}

$\mathrm{W}(\mathrm{S})$ and $\mathrm{W}(\mathrm{U})$ determine the amounts of waste collected and the total amounts of waste used in the waste treatment sectors. They do not determine how a certain waste type produced by a certain sector is treated. In order to make this correspondence between generation and treatment at sector level, an additional table is needed that determines waste treatment rates per waste type. The so-called waste treatment allocation table (S), introduced by Nakamura and Kondo (2002), is a waste treatment by waste type table whose components $s_{i k}$ show the share of waste type $k$ that is treated by a certain treatment method $i$. The sum of waste treatment shares for a specific waste type $k$ is 1 .

To determine the waste-specific treatment rates, we used various sources. Data on the destination of waste from economic activities is taken from the waste register (Bruxelles Environnement, 2016), a monitoring study (RECYDATA, 2014), and based on direct contacts with waste collectors and waste treatment facilities. For household and assimilated waste, data from the public agency ABP that monitors the treatment of MSW is used (Agence Bruxelles Proprété (ABP), 2016). The use of such datasets to 
Table 4

Waste treatment allocation table (S1) for economic activities.

\begin{tabular}{|c|c|c|c|c|c|c|c|c|c|c|}
\hline & Glass & Inert & Metals & Food & Paper & Plastic & Textile & Wood & Garden & Other \\
\hline Prep. for mat. rec. & 0.00 & 0.26 & 0.45 & 0.00 & 0.16 & 0.00 & 0.00 & 0.00 & 0.00 & 0.00 \\
\hline Reuse & 0.00 & 0.00 & 0.00 & 0.00 & 0.00 & 0.00 & 0.00 & 0.00 & 0.00 & 0.00 \\
\hline Incineration & 0.35 & 0.01 & 0.07 & 0.89 & 0.30 & 0.75 & 1.00 & 0.33 & 0.30 & 0.85 \\
\hline Composting & 0.00 & 0.00 & 0.00 & 0.00 & 0.00 & 0.00 & 0.00 & 0.00 & 0.21 & 0.00 \\
\hline Ex. to mat. rec. & 0.65 & 0.42 & 0.49 & 0.03 & 0.55 & 0.02 & 0.00 & 0.45 & 0.00 & 0.15 \\
\hline Ex. to inc. & 0.00 & 0.00 & 0.00 & 0.00 & 0.00 & 0.00 & 0.00 & 0.06 & 0.00 & 0.00 \\
\hline Ex. to comp. & 0.00 & 0.00 & 0.00 & 0.00 & 0.00 & 0.00 & 0.00 & 0.00 & 0.50 & 0.00 \\
\hline Ex. to landf. & 0.00 & 0.13 & 0.00 & 0.00 & 0.00 & 0.00 & 0.00 & 0.00 & 0.00 & 0.00 \\
\hline Ex. to AD. & 0.00 & 0.00 & 0.00 & 0.08 & 0.00 & 0.00 & 0.00 & 0.00 & 0.00 & 0.00 \\
\hline Ex. to unk. & 0.00 & 0.18 & 0.00 & 0.00 & 0.00 & 0.22 & 0.00 & 0.16 & 0.00 & 0.00 \\
\hline Ex. to reuse & 0.00 & 0.00 & 0.00 & 0.00 & 0.00 & 0.00 & 0.00 & 0.00 & 0.00 & 0.00 \\
\hline
\end{tabular}

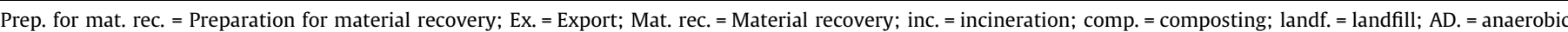
digestion; unk. = unknown.

Table 5

Waste treatment allocation table (S2) for households.

\begin{tabular}{|c|c|c|c|c|c|c|c|c|c|c|}
\hline & Glass & Inert & Metals & Food & Paper & Plastic & Textile & Wood & Garden & Other \\
\hline Prep. for mat. rec & 0.00 & 0.27 & 0.47 & 0.00 & 0.55 & 0.10 & 0.00 & 0.00 & 0.00 & 0.00 \\
\hline Reuse & 0.00 & 0.00 & 0.00 & 0.00 & 0.00 & 0.00 & 0.01 & 0.11 & 0.05 & 0.00 \\
\hline Incineration & 0.20 & 0.00 & 0.09 & 1.00 & 0.45 & 0.52 & 0.75 & 0.45 & 0.44 & 0.85 \\
\hline Composting & 0.00 & 0.00 & 0.00 & 0.00 & 0.00 & 0.00 & 0.00 & 0.00 & 0.56 & 0.00 \\
\hline Ex. to mat. rec. & 0.80 & 0.73 & 0.43 & 0.00 & 0.00 & 0.37 & 0.04 & 0.50 & 0.00 & 0.15 \\
\hline Ex. to inc. & 0.00 & 0.00 & 0.00 & 0.00 & 0.00 & 0.00 & 0.00 & 0.00 & 0.00 & 0.00 \\
\hline Ex. to comp. & 0.00 & 0.00 & 0.00 & 0.00 & 0.00 & 0.00 & 0.00 & 0.00 & 0.00 & 0.00 \\
\hline Ex. to landf. & 0.00 & 0.00 & 0.00 & 0.00 & 0.00 & 0.00 & 0.00 & 0.00 & 0.00 & 0.00 \\
\hline Ex. to AD. & 0.00 & 0.00 & 0.00 & 0.00 & 0.00 & 0.00 & 0.00 & 0.00 & 0.00 & 0.00 \\
\hline Ex. to unk. & 0.00 & 0.00 & 0.00 & 0.00 & 0.00 & 0.00 & 0.00 & 0.00 & 0.00 & 0.00 \\
\hline Ex. to reuse & 0.00 & 0.00 & 0.00 & 0.00 & 0.00 & 0.00 & 0.10 & 0.00 & 0.00 & 0.00 \\
\hline
\end{tabular}

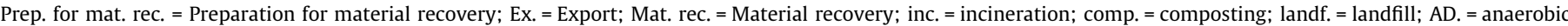
digestion; unk. = unknown.

construct the waste treatment allocation table could be a potential approach for other cities as well ${ }^{4}$.

After determining the treatment processes for an aggregated waste flows (for example mixed residual waste), the flows were disaggregated per waste type. Table 4 presents the waste treatment shares per waste type for economic activities, Table 5 for households. We distinguished the local treatment modes (preparation for material recovery, reuse, incineration and composting) and the exterior treatment processes which include also anaerobic digestion, landfill and the category 'unknown' if the final destination of the waste could not be determined. The low landfill rate is a result of Belgium's high landfill tax (one of the highest landfill taxes in Europe), combined with a landfill ban for several selected waste streams (Gentil, 2013).

\subsection{Waste supply to treatment table}

When multiplying (S) from the left by $\mathrm{W}(\mathrm{S})$, we receive the waste supply to treatment table $(\mathrm{W}(\mathrm{ST}))$. More precisely, the treatment shares for economic activities ( $s_{i k}$ from S1) are multiplied by the waste collected from economic activities $\left(w(s)_{k j}\right)$. Accordingly, the treatment shares for households $\left(s_{i k}\right.$ from S2) are multiplied by waste collected from households $\left(w(s)_{k f}\right)$. Table 6 shows the structure of the resulting table. It is a waste treatment by economic

\footnotetext{
${ }^{4}$ Waste registers, which seem to be available in many cities, have the purpose to register waste carriers, brokers and dealers. These waste service providers have to declare the amount (in mass) and type of collected waste, and the destination of the waste. In the specific case of Brussels, an anonymized version of this dataset could be accessed by the researchers, but it needed to be combined with other data sources (from monitoring studies and direct contacts with waste collectors and waste treatment facilities) to identify and solve declarations errors and eliminate double counting (Towa et al. 2016).
}

activity table whose components $w(s t)_{i j}$ determine the amount of waste, supplied by each sector, that are sent to a specific waste treatment activity. The total amount of waste sent to treatment $w(s t)_{k}$ is given by

$w(s t)_{k}=\sum_{j} w(s t)_{i j}+w(s t)_{i f}$

The mass balance between the waste supply, use and supply to treatment table is given by

$\sum_{k} w(s)_{k}=\sum_{k} w(u)_{k}=\sum_{k} w(s t)_{k}$

\subsection{Data aggregation}

To visualise the flows of waste from origin to their destination we constructed a Sankey diagram based on aggregated data from Table 7 and 9. Sankey diagrams visualise energy or material flows by scaling the size of the flows (arrows) proportional to the flow quantity (Schmidt, 2008).

For the purpose of clarity, the 81 economic activities have been aggregated into 10 groups, such as primary industries, manufacturing, construction, etc. The correspondence table (supplement 2) shows the alignment of economic activities to the 10 aggregated groups. We mainly follow the aggregation proposed by the hierarchical levels used in the NACE system, but extended the group further if the waste amount was too small to be displayed (example: the 'energy and water' sector was included into 'manufacturing'). In addition to the 10 aggregated economic activities, we added the household sector and a further grouped sector called 'nonspecified economic activity'. This sector contains flows which could not be aligned to a specific economic activity. 
Table 6

Waste supply to treatment table.

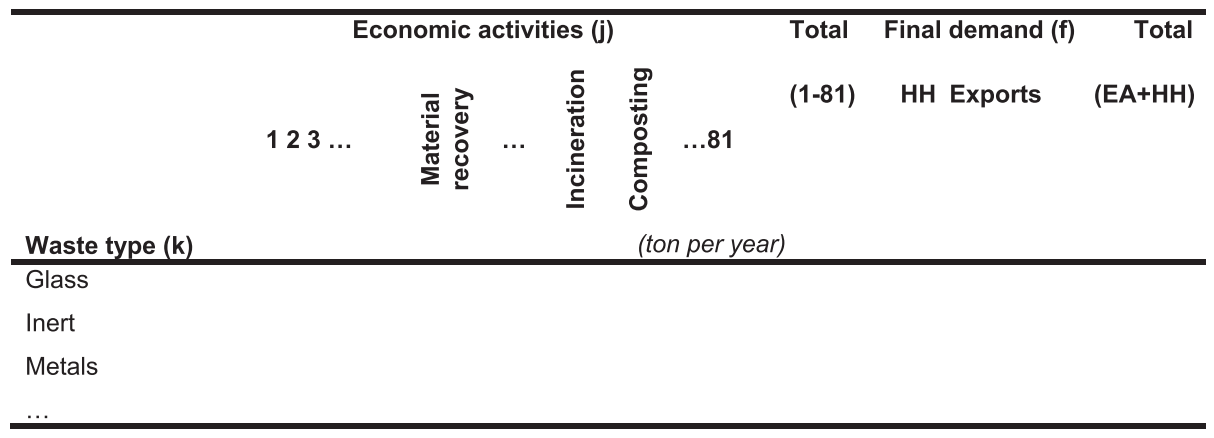

$\mathrm{HH}=$ Households, $\mathrm{EA}=$ Economic activity.

In order to visualise local material cycles we also added to the diagram the flows of the secondary waste from incineration (i.e. bottom ash, fly ash, metal residues etc.) and flows of secondary raw materials (recovered materials like sorted PET) produced in Brussels. The numerical tables behind the Sankey are given in supplement 3.

\subsection{Waste performance indicators}

To measure and compare the waste performance of the city's sectors, the two indicators 'waste production intensity' and 'waste treatment intensity' are chosen, because they measure two important aspects of a sector's performance: the sector's waste (in)efficiency in terms of amount of waste and type of treatment. The waste production intensity reflects the sector's production (in)efficiency and is expressed as a ratio between waste and production. It is calculated by dividing each component of the waste supply table $w(s)_{k j}$ (see 2.2 ) by the economic activity output $x_{j}$ from Brussels' supply table. The waste intensity is measured in ton per M€ sector output.

In order to take into account not only the amounts of generated waste, but also the type of treatment, the waste treatment intensity is used as second indicator. It refers to the amount of waste produced by a sector (in ton) that is sent to a specific treatment (for example to incineration or recycling). It is calculated by dividing each component of the supply to treatment table $w(s t)_{i j}(2.4)$ by the economic activity output $x_{j}$ from Brussels' supply table. The waste treatment intensity is also measured in ton per M€ sector output. Since the economic sector output is only available for 2010, the waste coefficients are calculated for 2010.

\section{Results and discussion}

\subsection{Waste flow analysis}

\subsubsection{Waste supply and use tables}

The results of the waste supply table for Brussels are shown in Table 7 . The ten waste types are broad categories containing different 'product' types produced by households and economic activities. For example, 'glass' includes flat glass from end of life vehicles and from C\&D activities, but also packaging glass disposed by households and the hotels and restaurant sector. The category 'inert' contains concrete, bricks, tiles and ceramics, inert mixture, asphalt, soil and stones. The category 'other' is a mixed fraction consisting mostly of 'complex packaging', 'fine particles' or 'street cleaning residues'.

The total amount of waste collected in 2014 is around 1.5 million tons, from which $71 \%$ is generated by economic activities and
$29 \%$ by households. Table 7 shows that households are the most important contributor for glass, food, textile and garden waste, while inert, metal and paper and cardboard are mainly produced by economic activities.

The sector-specific results are too detailed to be reproduced here, but available in the supplementary material (supplement $4)$. The results show that only for inert waste a large share $(31 \%$ of inert waste) can be aligned to one particular sector, the construction sector. For the other waste types, the amounts are more widely distributed over economic activities. For example, for paper waste, the public administration, financial intermediation and the other business services have a share of $15 \%, 11 \%$ and $9 \%$ respectively and the remaining part is distributed over 62 economic activities.

When discussing the quality of this detailed sector repartition, we point to the following sources of uncertainties: First, for certain sectors the local economic output specified in the supply table could be higher than their real production (so called 'head quarter problem') and second, the national waste intensity could under- or overestimate the regional waste intensity. Previous comparison between estimations based on waste coefficient approach and statistical data (Zeller et al., 2018) have shown that uncertainties occur mainly for metals, glass and inert waste.

Table 8 shows the amount of waste used in the local waste treatment facilities (i.e. input capacities) and the amount of waste exported to waste treatment facilities located out of Brussels. Around $770 \mathrm{kt}$ of waste (50\% of the total) is treated in Brussels, the remaining $50 \%$ is directly exported. Regarding the data quality, it has to be mentioned that the totals for incineration and composting represent accurate numbers measured by the treatment facilities, while the quantity for the 'preparation for material recovery' sector and the detailed, waste-type specific inputs represents estimations obtained from the sources previously described (Agence Bruxelles Proprété (ABP), 2016; Bruxelles Propreté, 2016; RECYDATA, 2017, 2014).

Table 9 is the waste supply to treatment table that shows treatment- and sector-specific results. Most waste collected from households is used in the local treatment facilities while waste collected from economic activities is mainly exported. The treatment options 'export to incineration, unknown, landfill and compost' occur for waste from economic activities only. These variations in treatment between economic activities and the household sector result from the different collection schemes and actors (public/private) responsible for the collection of waste. When comparing the amount of waste sent to the local 'preparation of material recovery' sector and to the local incinerator, indicated in Table 9, with the corresponding data from Table 8, we find that the calculated amounts in Table 9 are slightly lower than the ones 'measured' in the use tables. This indicates that incineration rates and material 
Table 7

Waste supply table (Brussels 2014).

\begin{tabular}{|c|c|c|c|c|c|}
\hline Waste type (k) & $\begin{array}{l}\text { Economic activities (j) } \\
123 \ldots 81\end{array}$ & $\begin{array}{l}\text { Total } \\
(1-81)\end{array}$ & $\begin{array}{l}\text { Final demand } \\
\mathrm{HH} \\
\text { (ton per year) }\end{array}$ & Imports & $\begin{array}{l}\text { Total } \\
\mathrm{EA}+\mathrm{HH}\end{array}$ \\
\hline Glass & & 14,099 & 24,998 & - & 39,097 \\
\hline Inert & & 556,608 & 96,260 & - & 652,869 \\
\hline Metals & & 167,232 & 33,084 & - & 200,317 \\
\hline Food waste & & 55,000 & 105,014 & - & 160,014 \\
\hline Paper \& cardboard & & 126,315 & 60,586 & - & 186,900 \\
\hline Plastic & & 57,517 & 45,108 & - & 102,625 \\
\hline Textile & & 11,132 & 14,528 & - & 25,660 \\
\hline Wood & & 42,789 & 20,487 & - & 63,276 \\
\hline Garden waste & & 14,856 & 26,449 & - & 41,305 \\
\hline Other & & 39,634 & 26,924 & - & 66,558 \\
\hline Total & & $1,085,183$ & 453,437 & - & $1,538,620$ \\
\hline
\end{tabular}

$\mathrm{HH}=$ Households, $\mathrm{EA}=$ Economic activity.

Table 8

Waste use table (Brussels 2014).

\begin{tabular}{|c|c|c|c|c|c|c|c|c|c|}
\hline \multirow[t]{2}{*}{ Waste type (k) } & \multicolumn{5}{|c|}{ Economic activities $(\mathrm{j})$} & \multirow{2}{*}{$\begin{array}{l}\text { Total } \\
1-81\end{array}$} & \multicolumn{2}{|c|}{ Final demand } & \multirow{2}{*}{$\begin{array}{l}\text { Total } \\
\text { EA + Exp. }\end{array}$} \\
\hline & $123 \ldots$ & Mat. rec. & Inc. & $\begin{array}{l}\text { Comp. } \\
\text { (ton per year) }\end{array}$ & $\ldots 81$ & & $\mathrm{HH}$ & Exp. & \\
\hline Glass & & - & 9,806 & - & & 9,806 & - & 29,291 & 39,097 \\
\hline Inert & & 177,500 & 11,132 & - & & 188,632 & - & 464.236 & 652,869 \\
\hline Metals & & 90,493 & 11,504 & - & & 101,997 & - & 98,320 & 200,317 \\
\hline Food waste & & - & 153,337 & - & & 153,337 & - & 6,677 & 160,014 \\
\hline Paper \& cardboard & & 51,603 & 64,599 & - & & 116,202 & - & 70,699 & 186,900 \\
\hline Plastic & & 12,226 & 64,899 & - & & 77,126 & - & 25,499 & 102,625 \\
\hline Textile & & 1,481 & 21,677 & - & & 23,158 & - & 2,502 & 25,660 \\
\hline Wood & & - & 13,359 & - & & 13,359 & - & 49,917 & 63,276 \\
\hline Garden waste & & - & 16,111 & 17,839 & & 33,950 & - & 7,355 & 41,305 \\
\hline Other & & - & 56,175 & - & & 56,175 & - & 10,382 & 66558 \\
\hline Total & & 333,302 & 422,600 & 17,839 & & 773.741 & - & 764.879 & $1,538,620$ \\
\hline
\end{tabular}

Mat. rec. = Preparation for material recovery; Inc. = incineration; Comp. = composting; HH = Households; EA = Economic activities; Exp. = Export.

Table 9

Waste supply to treatment table (Brussels 2014).

\begin{tabular}{|c|c|c|c|c|c|}
\hline Waste to treatment (i) & $\begin{array}{l}\text { Economic activities }(\mathrm{j}) \\
123 \ldots 81\end{array}$ & $\begin{array}{l}\text { Total } \\
(1-81)\end{array}$ & $\begin{array}{l}\text { Final demand } \\
\mathrm{HH} \\
\text { (ton per year) }\end{array}$ & Imports & $\begin{array}{l}\text { Total } \\
\mathrm{EA}+\mathrm{HH}\end{array}$ \\
\hline Prep. for material recovery & & 239,862 & 79,590 & - & 319,452 \\
\hline Reuse & & 443 & 3,186 & - & 3,629 \\
\hline Incineration & & 214,085 & 218,020 & - & 432,105 \\
\hline Composting & & 3,048 & 14,791 & - & 17,839 \\
\hline Ex. to mat. recovery & & 421,235 & 136,236 & - & 557,472 \\
\hline Ex. to inc. & & 2,540 & 0 & - & 2,540 \\
\hline Ex. to comp. & & 7,355 & 0 & - & 7,355 \\
\hline Ex. to landfill & & 72,359 & 0 & - & 72,359 \\
\hline Ex. to $\mathrm{AD}$. & & 4,145 & 179 & - & 4,325 \\
\hline Ex. to unkown & & 120,110 & 0 & - & 120,110 \\
\hline Ex. to reuse & & 0 & 1,434 & - & 1,434 \\
\hline Total & & $1,085,183$ & 453,437 & - & $1,538,620$ \\
\hline
\end{tabular}

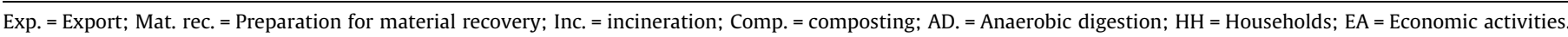

recovery shares that are used in the calculation are slightly underestimated for certain waste fractions. However, the overall mass balance between the three tables (Eq. (4)) is maintained.

\subsubsection{Waste flow analysis (sankey diagram)}

To represent waste flows in a Sankey diagram, we used aggregated versions of Table 7 and Table 9 (2.5.). On the left of the diagram (Fig. 1) the origin of waste is shown, represented by 12 sector groups. The size of each sector box represents the contribution of each sector to the total amount of waste collected in Brussels. We observe that households and construction are the most important contributing sectors to the total waste flow, representing $29 \%$ and $16 \%$ respectively. The composition of each sector's waste flow is represented by several single flow arrows leaving the sector box. We can see that the collected waste from households is heterogeneously composed, in contrast to the waste from the construction sector that is dominated by inert waste.

The single waste flows end in a waste treatment activity, which might be located within or outside of Brussels. The sum flow arrows indicate the contribution of each waste treatment activity to the overall waste management system: $27 \%$ of the total collected waste goes to the incinerator, $11 \%$ to inert recovery, $10 \%$ to other intermediate treatment processes (such as PMD, paper and textile sorting and metal recovery) and $1 \%$ to the city's composting 


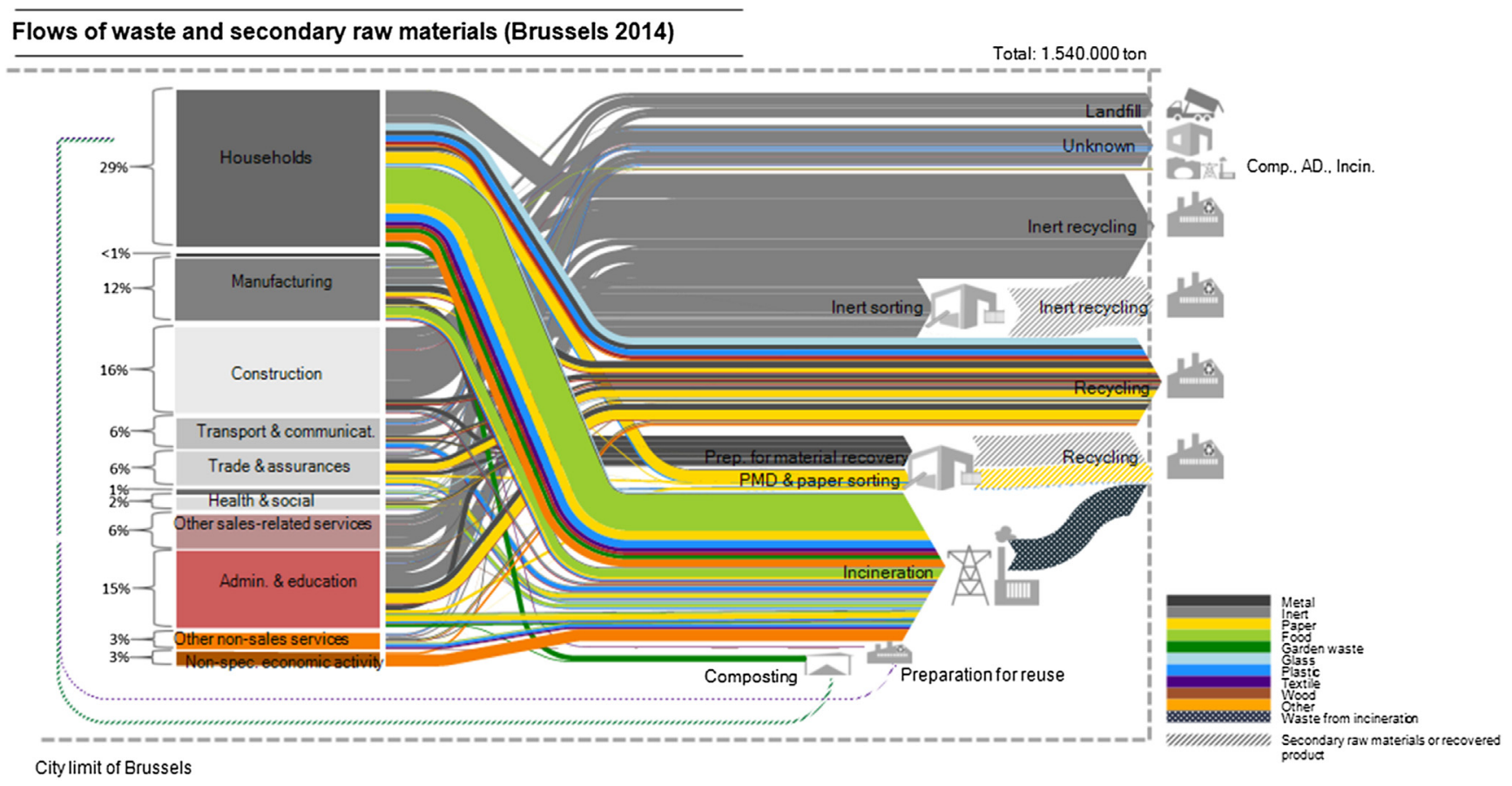

Comp.= composting; Inc. $=$ incineration; AD.= Anaerobic digestion

Fig. 1. Sankey diagram of waste and secondary raw material flows (Brussels 2014). Comp. = composting; Inc. = incineration; AD. = Anaerobic digestion.

facility. Thus, in total around 50\% of the collected waste is treated within the city limits. The remaining waste is sent out of Brussels to be treated: $5 \%$ goes to landfill ${ }^{5}, 36 \%$ is recycled and the remaining $9 \%$ is subject to other treatment processes (composting, anaerobic digestion, incineration and unknown). In addition to all of these primary waste flows, we also included the secondary waste flow from incineration indicating the proportion that is landfilled or sent to recycling.

The diagonal-shaded flows in Fig. 1 show secondary raw materials or products recovered from the intermediate treatment processes. These materials and products are mostly exported to recycling facilities in Belgium, Europe or the rest of the world, with only a small amount being reused at city level: $6 \mathrm{kt}$ of compost (from 18kt of garden waste, $64 \%$ sold to users in Brussels), $1.5 \mathrm{kt}$ of textiles, $1 \mathrm{kt}$ of wood, $0.6 \mathrm{kt}$ of plastics and $0.3 \mathrm{kt}$ of metals. This means that less than $1 \%$ of the total collected waste is used in a way that closes material cycles at city level. In addition to these local material cycles, the incineration plant with energy recovery could be considered as a local energy cycle. Around 5\% of Brussels' households can be supplied with electricity from the incinerator. This energy flow is not represented in this mass-related Sankey diagram.

The sum flow arrows for waste and secondary raw material on the right of the diagram show the current state of waste treatment in terms of the quantity dealt with by each treatment mode and whether this occurs within or outside the city. Nonetheless, as previously mentioned, the data (and therefore by definition the analysis) has certain limitations. It is based on the quantities of collected waste and does not take account of products being reused before collection. For example, this is why we see textile reuse in the form of clothes collected in containers and afterwards (partly) reused, but not clothes sold second-hand. Likewise, the data does not account for products that are (re-)sold on markets, sold between individuals or that are donated. Due to the variety of

\footnotetext{
${ }^{5}$ The low landfill rate is a general pattern in Belgium, where around $8 \%$ of the total waste was landfilled in 2014 (Eurostat, 2018d).
}

products and reuse exchange possibilities, this part of the CE which is already in place could not be quantified and is not represented in the diagram ${ }^{6}$.

Furthermore, since the diagram aims to present the origin and final destination of waste flows, intermediate collection points or flows between the waste treatment facilities are not illustrated. For example, sorting residues from the PMD and paper sorting facility that are sent to incineration are not illustrated as a separate flow between sorting facility and incinerator, but included in the input flows to the incineration plant. In reality, 250 registered actors participate in waste collection and treatment in Brussels, and various interactions occur between actors.

\subsection{Waste performance analysis}

In this section we analyse the waste performance of the city's sectors based on two indicators: the waste production and the waste treatment intensity (2.6).

Table 10 shows the waste production intensity (measured in ton/M€) for the aggregated sectors (see 2.5). Since the primary sector has almost no practical relevance for Brussels, we can exclude it from the discussion. The results show that the service sectors have a lower waste production intensity (between 2.72 ton/M€ to 8.86 ton/M€) compared to the other sectors (up to 41.31 ton/M€). The waste intensity of the manufacturing sector is slightly lower (7.27 ton/M€) than the transport and communication sector. This indicates that Brussels' manufacturing sector has few productionintensive industries. The household sector has the second highest waste production intensity. The highest intensity occurs for the construction sector, due to its high share of (heavy) inert waste.

When comparing sectors by waste type, we find highest intensity for glass waste in the Horeca sector. For inert, metals and wood waste the waste production intensity is highest in the construction

\footnotetext{
${ }^{6}$ An estimation of the second hand market in UK has shown amounts of around $180 \mathrm{kt}$ of products sold on car boot and furniture reuse markets (Gregson et al., 2013) which represents $0.1 \%$ compared to the annually non-hazardous waste generated.
} 
Table 10

Waste production intensity (in ton/M€).

\begin{tabular}{|c|c|c|c|c|c|c|c|c|c|c|}
\hline & Glass & Inert & Metals & Food & Paper & Plastic & Textile & Wood & Garden & Total \\
\hline & \multicolumn{10}{|c|}{ (ton per $M €)$} \\
\hline Primary sector & 0.38 & 189.92 & 4.64 & 0.10 & 0.22 & 0.74 & 0.01 & 0.19 & 0.00 & 196.21 \\
\hline Manufacturing & 0.08 & 2.74 & 1.64 & 1.19 & 0.90 & 0.30 & 0.05 & 0.36 & 0.00 & 7.27 \\
\hline Construction & 0.14 & 33.58 & 5.12 & 0.01 & 0.27 & 0.44 & 0.02 & 1.74 & 0.00 & 41.31 \\
\hline Trans. \& com. & 0.01 & 4.13 & 1.50 & 0.01 & 0.32 & 1.89 & 0.16 & 0.83 & 0.00 & 8.86 \\
\hline Trade $\&$ ass. & 0.05 & 0.55 & 0.67 & 0.13 & 1.00 & 0.17 & 0.05 & 0.10 & 0.00 & 2.72 \\
\hline Horeca & 2.08 & 0.19 & 0.22 & 1.85 & 0.08 & 1.48 & 0.21 & 0.30 & 0.00 & 6.41 \\
\hline Health \& social & 0.17 & 1.37 & 1.60 & 1.91 & 0.62 & 0.66 & 0.22 & 0.44 & 0.00 & 6.99 \\
\hline Other sale-rel. & 0.01 & 1.57 & 0.06 & 0.00 & 0.03 & 0.01 & 0.00 & 0.04 & 0.00 & 1.72 \\
\hline Admin. \& edu. & 0.06 & 2.65 & 0.94 & 0.18 & 1.54 & 0.23 & 0.02 & 0.18 & 0.45 & 6.24 \\
\hline Oth. non-sale & 0.08 & 1.37 & 0.89 & 0.54 & 0.62 & 1.74 & 0.81 & 0.77 & 0.00 & 6.82 \\
\hline Households & 1.30 & 4.99 & 1.45 & 5.41 & 3.48 & 2.18 & 0.57 & 0.82 & 1.08 & 21.28 \\
\hline
\end{tabular}

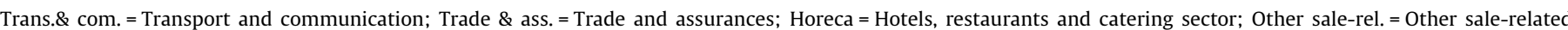
services; Admin. \& edu. = Administration and education; Oth. non-sale $=$ Other non-sale services.

sector; for food, paper and plastic waste in the household sector and for textile waste in the sector 'other non-sales services'.

Table 11 shows the waste treatment intensity (measured in ton/M€) for the aggregated sectors. Again, we can ignore the results for the primary sector. The treatment intensity results from the specific mix of waste produced by a sector and the waste-type specific treatment rates. Households show the highest intensity of incineration, but also second highest intensity of local material recovery. The construction sector has highest local material recovery rates (i.e. preparation for material recovery). The regional material recovery consists mainly of sorting and crushing activities of the inert fraction. The produced recycled aggregates are used in various applications, for instance, for road base and filling materials in road construction (downcycling).

The two presented indicators show the direct waste intensity, i.e. the amount of waste produced directly by an economic activity or households, without including waste generated upstream in the supply chain as a result of products supplied to the sector. The direct waste production intensity has been analysed by various authors, but the comparison of values is difficult due to differences in sector classification and monetary reference values. For example, Reynolds et al. (2014) found highest waste intensity for the construction sector, but in the aggregated results it is classified as a service sector, so that service sectors have highest direct waste intensities. High direct waste intensities for the primary, construction, and transport and communication sectors were also found by Reynolds et al. (2014) and Nakamura et al. (2007). Regarding the waste treatment intensity, comparisons with other studies reveal strong differences due to different waste treatment schemes established in the respective region under study. For example, the comparison between countries in Tisserant et al. (2017) reveals that recycling is the dominant treatment method in many European countries while it is landfill in, for example, Brazil, Mexico or Russia, and incineration in Japan.

\subsection{Circular economy valorisation and waste prevention potential}

The results from waste supply and use tables and the associated Sankey diagram were used to identify the non-exploited valorisation potential of Brussels' waste flows. This is important information for decision-makers implementing CE models. Regarding the ranking of treatment/valorisation options, we rely on the generalised environmental ranking of the waste hierarchy (see 1.1). Since waste prevention at source is the highest priority in the European and regional waste plans, we also interpreted the results in terms of their waste prevention potential.

When using Fig. 1 to identify potential waste prevention options, the sector contribution and waste composition analysis can provide useful information. The household sector was identified as the most important single contributor (at 29\%) and sector with second highest waste production intensity. The household sector is also the main focus of the current prevention strategy in Brussels' Waste Plan. However, when considering the total waste flow for the city, the importance of the remaining sectors (economic activities) becomes evident: Especially, the construction sector that is the second highest single contributor (at 16\%) and the sector with highest waste production intensity. The administration and education sector (third highest contributor, at 15\%) is

Table 11

Waste treatment intensity (in ton/M€).

\begin{tabular}{|c|c|c|c|c|c|c|c|c|c|}
\hline & \multicolumn{3}{|c|}{ Local treatment } & \multicolumn{5}{|l|}{ Export } & \multirow[t]{2}{*}{ Total } \\
\hline & $\begin{array}{l}\text { Mat.rec. } \\
\text { (ton/M€) }\end{array}$ & Inc. & Comp. & Mat. rec. & Inc. & Comp. & Landf. & Other & \\
\hline Primary sector & 51.69 & 3.11 & 0.00 & 82.31 & 0.01 & 0.00 & 24.69 & 34.39 & 196.21 \\
\hline Manufacturing & 1.59 & 1.89 & 0.00 & 2.70 & 0.02 & 0.00 & 0.36 & 0.71 & 7.27 \\
\hline Construction & 11.11 & 1.72 & 0.00 & 17.59 & 0.10 & 0.00 & 4.37 & 6.43 & 41.31 \\
\hline Trans. \& com & 1.81 & 2.10 & 0.00 & 3.06 & 0.05 & 0.00 & 0.54 & 1.30 & 8.86 \\
\hline Trade \& ass. & 0.60 & 0.69 & 0.00 & 1.19 & 0.01 & 0.00 & 0.07 & 0.16 & 2.72 \\
\hline Horeca & 0.17 & 3.82 & 0.00 & 1.82 & 0.02 & 0.00 & 0.02 & 0.55 & 6.41 \\
\hline Health and & 1.18 & 2.92 & 0.00 & 2.08 & 0.03 & 0.00 & 0.18 & 0.61 & 6.99 \\
\hline Other sale-rel. & 0.44 & 0.05 & 0.00 & 0.72 & 0.00 & 0.00 & 0.20 & 0.29 & 1.72 \\
\hline Admin. \& edu. & 1.35 & 1.11 & 0.09 & 2.54 & 0.01 & 0.22 & 0.34 & 0.57 & 6.24 \\
\hline Oth. non-sale & 0.86 & 3.12 & 0.00 & 1.80 & 0.05 & 0.00 & 0.18 & 0.80 & 6.82 \\
\hline Households & 4.30 & 11.48 & 0.60 & 6.92 & 0.00 & 0.00 & 0.00 & 0.01 & 23.32 \\
\hline
\end{tabular}

Mat. rec. = Material recycling; Inc. = Incineration; Comp. = composting; Landf. = Landfill.

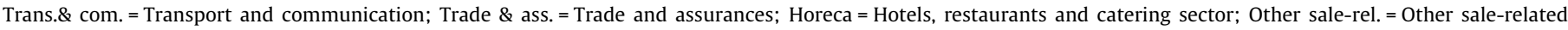
services; Admin. $\&$ edu. $=$ Administration and education; Oth. non-sale = Other non-sale services . 
also an important target sector for prevention measures. However, waste production intensity is lower than for example the one from households. The current Waste Plan provides quantitative prevention targets for food, paper and plastic, but when comparing these priorities with the composition of the waste flows, we note that the biggest flow in terms of mass is missing: the inert waste flow. Thus, it is clear that prevention policies need to be extended to all waste types and need to target economic activities as well.

When analysing the Sankey to identify new CE valorisation options with the priority on material recovery as suggested by the waste hierarchy, we focus on the waste treatment options that do not yet close material cycles (at local or global level). When applying this focus, we identify the possibility to redirect waste flows from the incinerator towards material reuse or recycling as measure with highest potential for Brussels. The reduction of waste flows going to the incinerator implies to increase the sorting efficiency at source, but also to expand the options of separate sorting. In this context, one stream is of particular importance due to its size and current treatment: the flow of food waste that is currently incinerated. Separate collection of this stream and valorisation in composting or anaerobic digestion could contribute to the closing of material cycles.

When discussing the options for the local CE valorisation potential, which is the focus adopted by the regional CE plan (1.3), it is helpful to distinguish between (i) preparation for material recovery (ii) and material recovery/reprocessing. The existing local facilities and actors, active in the collection and sorting of textiles, bulky waste, dismantling of WEEE or separation of plastic, paper and metals, belong to the first type of valorisation. The extension of such activities would imply to increase the amount of products with reuse or recycling potential, for example by improving access to collection points, by improving separation at source and extension of collections that maintain product quality. Furthermore, the local sorting/dismantling infrastructure could be extended, for example by an additional sorting line for plastics that are not separated and recycled today, bulky waste sorting or WEEE dismantling.

However, the implementation of the second type of valorisation can be limited at city scale by techno-economic constraints, as discussed in 1.2. Only specific waste types, such as organic wastes, mixed MSW, and demolition wastes are considered to be suitable for local material recycling and energy recovery. Thus, setting again the priority on the unexploited potential for material recovery, the highest CE valorisation potential occurs for organic waste by extending the existing composting capacity, to invest in anaerobic digestion or in a combination of both. The export of waste to composting, anaerobic digestion and incineration facilities outside of Brussels should be avoided if local valorisation is priority. However, potential changes in the waste management system need to be further assessed based on LCAs that consider not only the potential benefits of avoided transport, but also the efficiency of the complete waste treatment chain.

\section{Conclusions and outlook}

By using the waste input-output framework, we were able to close data gaps and to increase the level of detail in the waste data. This could contribute in empirically identifying the waste flows with the most promising CE valorisation potential for cities such as Brussels. The valorisation potential was identified here based on the generalised ranking of the waste hierarchy and needs to be completed by an LCA that compares the environmental performances of different valorisation options.

The datasets we developed enabled us to perform waste-type, sector- and treatment-specific analyses of urban waste flows.
Compared with conventional EW-MFAs based on statistical data, the urban waste metabolism presented in this study is more detailed and offers more possibilities in terms of its application. However, this increase in detail comes at a cost; the procedures of data conversion, alignment and disaggregation inherently resulted in additional uncertainties. Highest uncertainties occur for metals, glass and inert waste amounts and their distribution over economic sectors.

Furthermore, a general limitation of the approach is that the starting point is the amount of collected waste and not the amount of used products. Thus, the role of CE measures based on products could not be fully captured in this study. This limitation could be reduced by extending the waste input-output framework to physical product flows.

In this study we have developed waste supply and use tables as independent tables appended to economic supply and use tables that monitor product flows. However, to use the full analytical power of IO analyses, i.e. to calculate waste footprints and environmental impacts, the integration of these tables into the product flow matrix is needed, as demonstrated in Lenzen and Reynolds (2014) and Nakamura and Kondo (2002).

This study could find few examples of systems which closed material cycles at city level. However, Brussels has adopted a CE plan in 2016 only. To increase the rates of reuse and of material recycling, we identified target streams and proposed measures to exploit the unused valorisation potential. However, when considering the context of cities with a highly urbanized terrain, it becomes evident that closing material cycles at city level may only work to a certain extent and is limited to certain flows. Thus we see the role of cities (such as Brussels) in a CE mainly as provider of reusable products, recyclable materials (such as paper, plastics, metals, glass) and nutrients from organic waste rather than circularity islands. Whether the closing of material cycles at city level has environmental benefits compared to the national or global level, needs to be further assessed based on comparative LCA studies.

\section{Acknowledgement}

This research is conducted in the frame of the BRUCETRA project funded by the Brussels' capital region - Innoviris (2015PRFB-3a).

\section{Appendix A. Supplementary material}

Supplementary data to this article can be found online at https://doi.org/10.1016/j.wasman.2018.10.034.

\section{References}

Ackerman, F., 2000. Waste management and climate change. Local Environ. 5, 223229. https://doi.org/10.1080/13549830050009373.

Agence Bruxelles Proprété (ABP), 2016. Household and assimilated waste collected by $\mathrm{ABP}$ and other collecters (detailed datasets Brussels 2014).

Agence Bruxelles Proprété (ABP), 2015. Analyse de poubelle- comparaison composition 2014-2015.

Athanassiadis, A., Bouillard, P., Crawford, R.H., Khan, A.Z., 2017. Towards a dynamic approach to urban metabolism: tracing the temporal evolution of Brussels urban metabolism from 1970 to 2010. J. Ind. Ecol. 21, 307-319. https://doi.org/ $10.1111 /$ jiec. 12451 .

Athanassiadis, A., Christis, M., Bouillard, P., Vercalsteren, A., Crawford, R.H., Khan, A. Z., 2016. Comparing a territorial-based and a consumption-based approach to assess the local and global environmental performance of cities. J. Clean. Prod. https://doi.org/10.1016/j.jclepro.2016.10.068.

Avio, C.G., Gorbi, S., Regoli, F., 2017. Plastics and microplastics in the oceans: from emerging pollutants to emerged threat. Blue Growth Mar. Environ. Saf. 128, 211. https://doi.org/10.1016/j.marenvres.2016.05.012.

BFP, IBSA, SVR, IWEPS, 2015. Tableaux élaborés dans le cadre de la convention "Tableaux entrées-sorties régionaux monétaires pour la Belgique pour l'année 2010." 
Browne, D., O'Regan, B., Moles, R., 2009. Assessment of total urban metabolism and metabolic inefficiency in an Irish city-region. Waste Manag. 29, 2765-2771. https://doi.org/10.1016/j.wasman.2009.05.008.

Brunner, P.H., Rechberger, H., 2004. Practical Handbook of Material Flow Analysis. Taylor \& Francis e-Library.

Bruxelles Environnement, 2016. Waste register 2014 (confidential datasets).

Bruxelles Environnement, 2010. Plan déchets: Plan de prévention et de gestion des déchets (Plan/Programme), IBGE.

Bruxelles Propreté, 2016. Analyse de poubelle: Comparaison composition 20132015.

Bruxelles Propreté, 2014. Rapport annuel 2014.

Chen, X., Fujita, T., Hayashi, Y., Kato, H., Geng, Y., 2014. Determining optimal resource recycling boundary at regional level: a case study on Tokyo Metropolitan Area in Japan. Eur. J. Oper. Res. Eco-Efficient Green Supply Chain Manag. 233, 337-348. https://doi.org/10.1016/j.ejor.2013.01.054.

Chen, X., Fujita, T., Ohnishi, S., Fujii, M., Geng, Y., 2012. The impact of scale, recycling boundary, and type of waste on symbiosis and recycling. J. Ind. Ecol. 16, 129141. https://doi.org/10.1111/j.1530-9290.2011.00422.x.

Chifari, R., Lo Piano, S., Bukkens, S.G.F., Giampietro, M., 2016. A holistic framework for the integrated assessment of urban waste management systems. Ecol. Indic. https://doi.org/10.1016/j.ecolind.2016.03.006.

D'Alisa, G., Di Nola, M.F., Giampietro, M., 2012. A multi-scale analysis of urban waste metabolism: density of waste disposed in Campania. J. Clean. Prod. 35, 59-70. https://doi.org/10.1016/j.jclepro.2012.05.017.

EC, 2015. (European Comission) Closing the loop - an EU action plan for the Circular Economy. Communication from the Commission to the European Parliament, the Council, the European Economic and Social Committee and the Committee of the Regions.

EC, 2008. DIRECTIVE 2008/98/EC OF THE EUROPEAN PARLIAMENT AND OF THE COUNCIL of 19 November 2008 on waste and repealing certain Directives.

Ellen MacArthur Foundation, 2017. Cities in the circular economy: an initial exploration.

Eurostat, 2018a. Municipal waste by NUTS 2 regions - pilot project data. http:// appsso.eurostat.ec.europa.eu/nui/show.do?dataset=env_rwas_gen

Eurostat, 2018b. Population density by NUTS 3 region. http://appsso.eurostat.ec. europa.eu/nui/show.do?dataset=demo_r_d3dens\&lang=en

Eurostat, 2018c. Gross value added at basic prices by NUTS 3 regions. http://appsso. eurostat.ec.europa.eu/nui/show.do?dataset=nama_10r_3gva\&lang=en

Eurostat, 2018d. Treatment of waste by waste category, hazardousness and waste management operations. http://appsso.eurostat.ec.europa.eu/nui/show. do?dataset $=E N V \_$WASTRT\&lang $=e n$

Eurostat, 2017. Land use overview by NUTS 2 regions. http://appsso.eurostat.ec. europa.eu/nui/show.do?dataset=lan_use ovw\&lang=en

Fang, K., Dong, L., Ren, J., Zhang, Q., Han, L., Fu, H., 2017. Carbon footprints of urban transition: tracking circular economy promotions in Guiyang. China. Ecol. Model. 365, 30-44. https://doi.org/10.1016/j.ecolmodel.2017.09.024.

Fry, J., Lenzen, M., Giurco, D., Pauliuk, S., 2016. An Australian multi-regional waste supply-use framework. J. Ind. Ecol. 20, 1295-1305. https://doi.org/10.1111/ jiec.12376.

Geng, Y., Tsuyoshi, F., Chen, X., 2010. Evaluation of innovative municipal solid waste management through urban symbiosis: a case study of Kawasaki. J. Clean. Prod. 18, 993-1000. https://doi.org/10.1016/j.jclepro.2010.03.003.

Gentil, E.C., 2013. Municipal Waste Management in Belgium. European Environment Agency.

Goldstein, B., Hauschild, M., Fernández, J., Birkved, M., 2016. Urban versus conventional agriculture, taxonomy of resource profiles: a review. Agron. Sustain. Dev. 36, 9. https://doi.org/10.1007/s13593-015-0348-4.

Gregson, N., Crang, M., Laws, J., Fleetwood, T., Holmes, H., 2013. Moving up the waste hierarchy: car boot sales, reuse exchange and the challenges of consumer culture to waste prevention. Resour. Conserv. Recycl. 77, 97-107. https://doi. org/10.1016/j.resconrec.2013.06.005.

Guibrunet, L., Sanzana Calvet, M., Castán Broto, V., 2016. Flows, system boundaries and the politics of urban metabolism: waste management in Mexico City and Santiago de Chile. Geoforum. https://doi.org/10.1016/j.geoforum.2016.10.011.

Hage, O., Söderholm, P., 2008. An econometric analysis of regional differences in household waste collection: the case of plastic packaging waste in Sweden. Waste Manag. 28, 1720-1731. https://doi.org/10.1016/j.wasman.2007.08.022.

Hoornweg, D., Bhada-Tata, P., Kennedy, C., 2013. Waste production must peak this century. Nature 502, 615-617.

Laurent, A., Bakas, I., Clavreul, J., Bernstad, A., Niero, M., Gentil, E., Hauschild, M.Z., Christensen, T.H., 2014. Review of LCA studies of solid waste management systems - Part I: lessons learned and perspectives. Waste Manag. 34, 573-588. https://doi.org/10.1016/j.wasman.2013.10.045.

Lenzen, M., Reynolds, C.J., 2014. A supply-use approach to waste input-output analysis. J. Ind. Ecol. 18, 212-226. https://doi.org/10.1111/jiec.12105.

Lu, J.-W., Zhang, S., Hai, J., Lei, M., 2017. Status and perspectives of municipal solid waste incineration in China: a comparison with developed regions. Waste Manag. 69, 170-186. https://doi.org/10.1016/j.wasman.2017.04.014.

Nakamura, S., Kondo, Y., 2002. Input-output analysis of waste management. J. Ind. Ecol. 6, 39-63. https://doi.org/10.1162/108819802320971632.

Nakamura, S., Nakajima, K., Kondo, Y., Nagasaka, T., 2007. The waste input-output approach to materials flow analysis. J. Ind. Ecol. 11, 50-63. https://doi.org/ 10.1162/jiec.2007.1290.
NTNU, TNO, SERI, Universiteit Leiden, WU, 2.-0 LCA Consultants, 2015. Exiobase [WWW Document]. URL http://www.exiobase.eu/ (accessed 7.16.16).

Petit-Boix, A., Leipold, S., 2018. Circular economy in cities: reviewing how environmental research aligns with local practices. J. Clean. Prod. 195, 12701281. https://doi.org/10.1016/j.jclepro.2018.05.281.

PREC, 2016. Programme régionale en economie circulaire 2016-2020-Mobiliser les ressources et minimiser les richesses perdues: Pour une économie régionale innovante.

Prendeville, S., Cherim, E., Bocken, N., 2017. Circular cities: mapping six cities in transition. Environ. Innov. Soc. Transit. https://doi.org/10.1016/j. eist.2017.03.002.

RECYDATA, 2017. Evaluation du potentiel d'amélioration du tri, de la collecte et du traitement des déchets professionnels tout-venant en région de BruxellesCapitale.

RECYDATA, 2014. Monitoring des quantités de déchets industriels générés dans la Région de Bruxelles-Capitale en 2010, 2011 et 2012 et de leurs modes de traitement.

Region de Bruxelles-Capitale, 2018. Plan de gestion des ressources et des déchets. Pour une consommation durable, sobre, locale et circulaire Pour une société zéro déchet. (Plan/Programme-Avant-Projet). IBGE.

Reynolds, C.J., Piantadosi, J., Boland, J., 2014. A waste supply-use analysis of australian waste flows. J. Econ. Struct. 3, 5. https://doi.org/10.1186/s40008-0140005-0.

Sanyé-Mengual, E., Cerón-Palma, I., Oliver-Solà, J., Montero, J.I., Rieradevall, J., 2013. Environmental analysis of the logistics of agricultural products from roof top greenhouses in Mediterranean urban areas. J. Sci. Food Agric. 93, 100-109. https://doi.org/10.1002/jsfa.5736.

Sanyé-Mengual, E., Oliver-Solà, J., Montero, J.I., Rieradevall, J., 2015. An environmental and economic life cycle assessment of rooftop greenhouse (RTG) implementation in Barcelona, Spain. Assessing new forms of urban agriculture from the greenhouse structure to the final product level. Int. J. Life Cycle Assess. 20, 350-366. https://doi.org/10.1007/s11367-014-0836-9.

Schmidt, M., 2008. The Sankey diagram in energy and material flow management. J. Ind. Ecol. 12, 173-185. https://doi.org/10.1111/j.1530-9290.2008.00015.x.

SEEA, 2014. United Nations, European Union, Food and Agriculture Organization of the United Nations, International Monetary Fund Organisation for Economic Cooperation and Development, The World Bank. System of EnvironmentalEconomic Accounting 2012 Central Framework

Sterr, T., Ott, T., 2004. The industrial region as a promising unit for eco-industria development-reflections, practical experience and establishment of innovative instruments to support industrial ecology. J. Clean. Prod. Appl. Ind. Ecol. 12, 947-965. https://doi.org/10.1016/j.jclepro.2004.02.029.

Sun, L., Li, H., Dong, L., Fang, K., Ren, J., Geng, Y., Fujii, M., Zhang, W., Zhang, N., Liu, Z. 2017. Eco-benefits assessment on urban industrial symbiosis based on material flows analysis and emergy evaluation approach: a case of Liuzhou city, China Sustainable development paths for resource-constrained process industries Resour. Conserv. Recycl. 119, 78-88. https://doi.org/10.1016/j. resconrec.2016.06.007.

Tisserant, A., Pauliuk, S., Merciai, S., Schmidt, J., Fry, J., Wood, R., Tukker, A., 2017 Solid waste and the circular economy: a global analysis of waste treatment and waste footprints. J. Ind. Ecol. 21, 628-640. https://doi.org/10.1111/jiec.12562.

Towa, E., Zeller, V., Degrez, M., Achten, W., 2017. Data mining of the waste collected in the Brussels Capital Region (Deliverable WP1).

Tsukui, M., Kagawa, S., Kondo, Y., 2015. Measuring the waste footprint of cities in Japan: an interregional waste input-output analysis. J. Econ. Struct. 4, 18 https://doi.org/10.1186/s40008-015-0027-2.

Tukker, A., de Koning, A., Wood, R., Hawkins, T., Lutter, S., Acosta, J., Cantuche, J.M.R. Bouwmeester, M. Oosterhaven, J. Drosdowski, T., Kuenen, J. 2013. Exiopol development and Illustrative analyses of a detailed global Mr Ee Sut/Iot. Econ. Syst. Res. 25, 50-70. https://doi.org/10.1080/09535314.2012.761952.

Van Berkel, R, Fujita, T. Hashimoto, S, Geng, Y, 2009. Industrial and urban symbiosis in Japan: analysis of the Eco-Town program 1997-2006. J. Environ. Manage. 90, 1544-1556. https://doi.org/10.1016/j.jenvman.2008.11.010.

Wang, N., Lee, J.C.K., Zhang, J., Chen, H., Li, H., 2018. Evaluation of Urban circular economy development: an empirical research of 40 cities in China. J. Clean. Prod. 180, 876-887. https://doi.org/10.1016/j.jclepro.2018.01.089.

Wilson, D., Rodic, L., Modak, P., Soos, R., Carpintero Rogero, A., Velis, C., Iyer, M., Simonett, O., Iswa, U., 2015. Global Waste Management Outlook (Report). UNEP and ISWA.

Wood, R., Stadler, K., Bulavskaya, T., Lutter, S., Giljum, S., de Koning, A., Kuenen, J. Schütz, H., Acosta-Fernández, J., Usubiaga, A., Simas, M., Ivanova, O., Weinzettel, J., Schmidt, J.H., Merciai, S., Tukker, A., 2014. Global sustainability accountingdeveloping EXIOBASE for multi-regional footprint analysis. Sustainability 7 138-163. https://doi.org/10.3390/su7010138.

Zeller, V., 2017. Evaluating environmental impacts from production and consumption at regional level with input-output life cycle assessment.

Zeller, V., Towa, E., Degrez, M., Achten, W.M.J., 2018. Integration of Waste Supply and Use Data into Regional Footprints: Case Study on the Generation and Use of Waste from Consumption and Production Activities in Brussels. 25th CIRP Life Cycle Eng. LCE Conf. 30 April - 2 May 2018 Cph. Den. 69, 100-105. https://doi. org/10.1016/j.procir.2017.11.116 